\title{
LAS PLANTAS CULTIVADAS Y EL ORIGEN DE LAS CULTURAS AGRICOLAS AMERICANAS
}

\author{
Salvador Canals Frau
}

De los tres grandes tipos de cultura que vemos existir en el mundo: el inferior o paleolítico, el medio o neolítico, y el superior o de la Civiiización, se puede decir que ninguno es originario, en su forma prístina, de América. Los tres nacieron en el Viejo Mundo, y es desde allí que vinieron con sus respectivos portadores. La llegada de los últimos se produjo en una serie de inmigraciones, aisladas o en cadena, cuyo número exacto es imposible de calcular, pero que nosotros reducimos a cuatro fundamentales corrientes ${ }^{1}$.

Que las más primitivas culturas americanas, o sean, las de tipo in-. ferior que desconocen la agricultura, ingresaran desde el nordeste de Asia, apenas si es discutido por nadie hoy día. Tampoco se discute la ruta que sus portadores hubieron de seguir. Hacia fines del Pleistoceno, que es la época en que hemos de situar a la primera corriente, la única vía posible era la del estrecho de Bering, y por allí han de haber pasado los primeros pobladores de América. Una serie de hallazgos de antiquísimas culturas como las de Sandía Cave y Folsom que se escalonan a lo largo de un corredor que va desde Alaska a México, nos señalan, además, la efectividad de esa ruta.

En cambio, no todo el mundo acepta que las culturas de tipo medio y superior, o sean aquellas que basan su economía en el cultivo, hayan también llegado desde el Viejo Mundo. Ni menos que lo hicieran a través del Océano Pacífico, que es la única posibilidad existente. Al menos es esto lo que debemos suponer dado que no se encuentran culturas agricolas en el norte del continente americano ni en el nordeste de Asia, ni es probable que las haya habido nunca, ya que las condiciones climáticas son allí adversas a todo cultivo. Por lo tanto, los portadores de las culturas agrícolas no pudieron seguir la ruta de las anteriores corrientes. Y esta es la causa también por la que muchos autores prefieran creer en la autoctonía de las culturas agrícolas americanas.

De acuerdo con los puntos de vista de estos autores, las culturas agrícolas americanas háabrían surgido por "evolución interna" de las anteriores $^{2}$. Mas, nadie nos ha explicado de manera plausible cual haya podido ser el curso de este proceso evolutivo. Es cierto que alguna vez se ha aludido al convencimiento a que habrían llegado un buen día ciertos pueblos americanos no agricultores, de que sólo haciendo producir alimentos a la tierra inculta podían aliviar la ham- 
bruna que estaban sufriendo. Lo cual es, naturalmente, una tontería. Pues, los pueblos que están pasando hambre o miseria son los menos dispuestos a buscar procedimientos nuevos que sólo en el futuro podrán proporcionarles ayuda. Sin contar que la necesidad no es siempre la madre de las invenciones ${ }^{3}$.

Más que tratar de establecer el modo y manera en que, independientemente de las del Viejo Mundo, habrían nacido en América las culturas agrícolas, se ha intentado demostrar la efectividad de su autoctonía. Y uno de los principales argumentos utilizados con ese fín es el de declarar originarias del continente americano todas las plantas que los indios cultivaban en la época del descubrimiento de América.

La argumentación suele ser la siguiente: $\mathrm{Si}$ se admitiese que los elementos de las culturas medias y superiores americanas vinieron del Viejo Mundo, traídos por grupos de inmigrantes poseedores de los principios del trabajo agrícola, no se explicaría que las plantas que esos pobladores cultivaran luego aquí, fueran distintas de las que ellos mismos cultivaban antes allá. Pues, es sabido que en las migraciones en grupo, los migrantes suelen llevar consigo los artefactos, las técnicas, las ideas y las costumbres que tenían en su país de orígen. Mas, en este caso, los pobladores habrían llevado consigo todas sus cosas menos las plantas alimenticias e industriales a que estaban acostumbrados. Pues, ni el trigo, la cebada o el arroz, ni ninguna otra planta domesticada de las que constituyen la base de la agricultura del Viejo Mundo, habría sido conocida aquí con anterioridad al Descubrimiento.

Hasta hace poco todavía se podía argüir así. Mas, hoy ya no es posible hacerlo. Las numerosas investigaciones realizadas en los últimos decenios, especialmente de parte de los botánicos, van paulatinámente cambiando el sencillo aspecto que el viejo problema tenía. Y como de él depende en gran parte el dilema sobre si hubo difusión desde el Viejo Mundo o invención independiente de las culturas medias $y$ superiores americanas, no estará de más que revisemos escuetamente los datos que tenemos sobre lugar de orígen y centro de domesticación de las principales plantas que cultivaban los indios en la época de su primer contacto con los europeos.

Americana es, por de pronto, la mandioca o yuca (Manihot utilíssima). Por lo general, y sobre la base de la gran concentración de es.pecies y variedades de esta planta que se encuentra en el Brasil, se considera a ese país como su verdadera patria. Hay, desde luego, autores que, como Sauer, ${ }^{4}$ prefieren las costas secas del Caribe. No se conoce la forma silvestre de la que procede. Y hace tanto tiempo que se cultiva por estaca, que ya ha perdido la capacidad de reproducirse por semilla.

El maní o cacahuete (Arachis hypogaea) procede muy probablemente del Brasil también, donde sus parientes silvestres se encuentran 
a lo largo de la región costanera desde Bahía a Rio de Janeiro. Se trata, portanto, de otra planta amazónica por su orígen y dispersión, aunque aparece también en viejas sepulturas de la costa del Perú y se encuentra igualmente en Méjico.

El aji o pimiento (Capsicum annuum) se considera americano también, aunque todavía no esté bien establecida la región de su orígen. En contra de otras opiniones, Mangelsdorf la cree natural del Brasil'.

Igualmente americano es el tabaco (Nicotiana tabacum) que se supone originado en las laderas de los Andes bolivianos. Más antigua que esa especie moderna y corriente es $N$. rustica, que tenía una gran difusión a través de la América indígena.

Y el tomate (Lysopersicum esculentum) se encuentra en el mismo caso que las anteriores. Parece ser mexicana.

La quínua (Chenopodium quinoa) es también americana por su orígen. Es de gran importancia alimenticia en las partes altas de la Cordillera de los Andes, donde generalmente sustituye al maíz. No se conocen sus parientes silvestres.

La papa (Solanum) es también netamente andina y americana. Las últimas investigaciones de un instituto oficial británico reconocen la existencia de numerosos especies, cuya respectiva área de cultivo se extiende desde Boyacá, en Colombia, hasta Cochabamba, en Bolivia. Antes se creyó que una subespecie chilena, la Solanum tuberosum chileanum era la forma más antigua; pero los últimos trabajos consideran a ésta derivada de especies peruanas o bolivianas ${ }^{6}$.

Los fríjoles o porotos (Phaseolus) son igualmente americanos. Aparecen en cuatro especies cultivadas. El fríjol común ( $P$. vulgaris) es una de ellas, y centro de su domesticación parece haber sido México. Otra conocida especie es el pallar ( $P$. lunatus), que muy probablemente tuvo su orígen en Guatemala; al menos es esta la única región donde se han encontrado ejemplares silvestres.

Las calabazas del género Cucurbita pertenecen también a este hemisferio, especialmente C. moschata (ayote), C. maxima (zapallo) y C. ficifolia (mexicana o victoria). Según Hcehne, la "moranga" del norte del Brasil, y la "geremú" del nordeste, corresponden a $C$. maxima y $C$. moschata, respectivamente ${ }^{7}$.

La palma pijibay (Bactris utilis, sinónimo Guilielma) se encuentra sobre todo en las tierras calientes colombianas y centroamericanas y, en las vertientes orientales de los Andes. No se conocen variedades silvestres, pero se supcne igualmente americana.

Finalmente, la arracacha (Arracacia xanthorrhiza), que se cultiva en Colombia y en algunas partes del Perú es también americana. En la alimentación de los Chibchas desempeñó un papel importante.

Aún se podrían nombrar algunas otras plantas cultivadas por los indios y que se consideran igualmente americanas. Mas, son ellas de poca importancia. 


\section{III}

Las que hasta ahora hemos mencionado tenían su cultivo limitado al continente americano, y todas ellas parecen ser originarias de este. mismo hemisferio. Por lo tanto, han de haber sido domesticadas aqui. Pero hay otro grupo, indudablemente menor, que aunque ignorándose en algún caso su país de orígen, está bien establecido que en época prehispánica se cultivaban tanto en el Viejo como en el Nuevo Murdo.

De entre este segundo grupo se debe nombrar ante todo al mate - calabacilla (Lagenaria). Es pianta indudablemente originaria del Viejo Mundo, pero se cultivaba también en América, adonde tienen que haberla traído, ya domesticada, los componentes de las últimas corrientes de población. Pues sus restos han sido hallados en los yacimientos arqueológicos de Huaca Prieta, Punta Pichalo y Arica ${ }^{9}$, y esto equivale a decir que su transferencia a este continente es anterior a las civilizaciones. Algunos autores supusieron que su presencia en América podía deberse a haber sido arrastrada hacia nuestras costas por las corrientes marinas. Pero si se considera que es planta cultígena, que depende enteramente de los cuidados del Hombre para su cultivo, se verá que es ello imposible. A menos que se admita, como muy bien ha expresado Sauer, que además de haber podido realizar el viaje sin detrimento alguno de sus cualidades vegetativas, hubiese habido en las playas americanas algún indio agricultor que la estaba esperando ${ }^{11}$.

Lo mismo sucede con el cocotero (Cocos nucifera). En la época del primer contacto de los españoles con las tierras americanas del lado del Pacífico, esta conocida palma, que se extiende ampliamente por todo el mundo oceánico, se cultivaba también en la parte de aquella costa que va desde Colombia a México. Es decir, en la parte del continente americano que da cara a Oceanía. Es muy probable, por tanto, que ella fuera también introducida de Polinesia o Indonesia.

Y en idéntica posición está también la batata (Ipomcea batatas). Generalmente se la tiene por americana, pero el asunto no está bien establecido. Se cultivaba, desde luego, en América, y se cultivaba igualmente en Polinesia. $Y$ hasta lleva allí el mismo nombre de cumata que tiene en Perú y Ecuador. No hay duda, pues, de que ella ha sido lievada o traída a través del Océano Pacífico, sin poder decir exactamente cuál haya sido el sentido de su propagación. Mas, de una u otra manera ella confirma nuevamente la posibilidad de que el Hombre, en sus viajes o migraciones llevara consigo algunas de las plantas que en su país de orígen estaban acostumbrados a cultivar.

También el maíz (Zea), que hasta hace poco apareciera como la planta americana por excelencia, tiene ahora una situación que está lejos de ser clara. La antigua suposición de que ella fuera originaria de Centroamérica ha quedado descartada en los últimos tiempos por razones puramente botánicas. Tampoco es muy seguro que se originara en la región Paraguay-Bolivia, como propusieran Mangelsdorf-Reeves ${ }^{1:}$. $\mathrm{Ni}$ menos en Colombia, cual sugiriera por motives etnográficos Birket- 
Smith $^{13}$. Y existen dudas serias acerca de su calidad de americana. Algunos indicios de peso señalan al maíz como originado más bien en el norte de la India o Birmania, es decir, en el Viejo Mundo. Por ejemplo, Zea mais no tiene en América antecesoras directas de las que pudiera descender. Su cultivo en el Asia meridional y oriental es muy antiguo, constando históricamente que en el siglo XVI, cuando en Europa el maiz no pasaba de ser una mera curiosidad botánica, ya se practicaba su cultivo en gran escala en la China. Sin contar que en el Asia meridional cuenta con numerosas especies y variedades con nomhre propio en las lenguas locales cada una. Parecería, pues, como si también esta planta procediera del Viejo Mundo y hubiese sido domesticada allí.

Estos pocos ejemplos de plantas simultáneamente cultivadas en el Viejo y en el Nuevo Mundo en tiempos prehispánicos nos muestran sin lugar a dudas que al menos ellas han sido transferidas de un continente a otro. Aquí no cabe recurrir al manido recurso de explicar su presericia simultánea en ambos hemisferios por medio de las invenciones independientes. Pues, no es posible que un mismo organismo vivo se originara reiteradamente en partes distintas del mundo. Y como tampoco es posible que esas plantas migraran solas, tienen que haber ocurrido migraciones humanas transoceánicas, y con ellas haberse realizado el correspondiente transplante de culturas.

A nuestro entender, lo que debe de haber ocurrido es que al producirse la llegada de gentes procedentes del sudeste de Asia y Polinesia a este continente, los migrantes llevaban consigo algunas plantas de las que estaban acostumbrados a cultivar. Una vez establecidos aqui, las siguieron cultivando, al tiempo que buscaban en la flora local especies adecuadas para ampliar el número de las cultivadas. Pues, nadie mejor que el cultivador avezado puede llevar a cultivación exitosa las especies nuevas.

Que esto no sólo es factible, sino poco menos que seguro, se evidencia al considerar el caso del algodón (Gossypium), del que hay especies asiáticas y especies americanas. Los estudios genéticos han demostrado que el conjunto puede clasificarse en tres grupos: un primer grupo es nativo del Viejo Mundo, donde sus componentes se encuentran tanto en estado siivestre como domesticado; estas plantas son de 13 cromosomas grandes. Un segundo grupo es americano, y sólo se encuentran en estado silvestre; tienen 13 cromosomas pequeños. Finalmente, el tercer grupo está constituído por dos especies americanas cultivadas, y una hawaiiana ( $G$. tomatosum) que es silvestre; las tres especies son de 26 cromosomas, 13 grandes y 13 chicos. Por lo tanto. este tercer grupo es de evidente formación híbrida, ya que lleva en sí la serie americana y la asiática de cromosomas. Su orígen debe explicarse admitiendo que una especie asiática, traída sin duda a través del Pacífico, estuvo algún tiempo en cultivo al lado de otra indígena americana. Y que una vez fcrmada por hibridización la forma tetraploide (es decir, de 26 cromosomas), esta se escindió $\in \mathrm{n}$ dos distintas varie- 
dades que, en el correr de los tiempos, se convirtieron en dos distintas. especies: la $G$. barbadense y la G. hirsutum ${ }^{14}$.

En consecuencia, el testimonio de las plantas cultivadas por los. indios en época prehispánica no sólo no se opone a la tesis que hace derivar del Viejo Mundo a las culturas agrícolas americanas, sino que la corrobora decididamente.

Y aún hay más. Este mismo testimonio, unido al de la arqueologia y etnografía, nos señalan también que las culturas agrícolas americanas. fueron traídas por dos distintas corrientes de población.

\section{NOTAS}

(1) CANALS FRAU S., Prehistoria de América. Buenos Aires 1950.

(2) Esto es lo que suponen hasta autores que, como el P. Cooper, admiten la posibilidad de los contactos culturales entre América y Oceinía. Véase COOPER J. M., Areal and temporal aspects of aboriginal South American culture, en Primitive Man, XV, 28 (1943).

(3) SAUER C. O., Agricultural origins and dispersals, pág. 21 (1952),

(4) SAUER C. O., Cultivated plants of South and Central America, en Handbook of South American Indians, VI, 507 (1950).

(5) MANGELSDORF P. C., REEVES R. G., The origin of Indian cort and its relatives, pág. 289 (1939).

(6) HAWKES J. G., Potato collection expeditions in Mexico and South America. Cambridge 1944.

(7) HOEHNE F. C., Botánica e agricultura no Brasil no século XVl. São Paulo 1937.

(8) BIRD J. B., Preceramic cultures in Chicama and Virú, en An appraisal of Peruvian archaeology, pág. 24 (1948) .

(9) BIRD J. B., Excavations in Northern Chile, en Anthropological Papers of the American Musenm of Natural History, XXXVIII (1943).

(10) UHLE M., Fundamentos étnicos de Tacna y Arica, en Boletin de la Sociedad de Estudios Americanos, II (1919).

(11) SAUER C. O., Cultivated Plants, etc., pág. 506.

(12) MANGELSDORF-REEVES, citado, pág. 250.

(13) BIRKET-SMITH K., The origin of maize cultivation, en Det kigl.Danske Videnskabernes Selskab, XXIX, 3 (1943).

(14) HUTCHINSON y COLABORADORES, The evolution of the cultivated cottons (1947). 